\section{Dimensional control of retardate memory ${ }^{1}$}

BONNIE M. MCBANE and DA VID ZEAMAN, University of Connecticut, Storrs, Conn. 06268

Stimulus dimensions of color and form are found to control the development of proactive interference in the learning and retention of two-choice visual discriminations by retardates. A change in the relevant dimension from form to color or from color to form, in a series of two-trial problems, results in a release from proaction. The dimensionality of control in retention parallels that found in attention.

A theoretically guided program of research on the visual discrimination learning of retardates has shown that the attention of these $S s$ is controlled by dimensions of stimuli, such as color, form, and position, rather than by specific cues of these dimensions [e.g., red-blue, square-cross, or left-right (Zeaman \& House, 1963; House \& Zeaman, 1963)]. The principal evidence for this comes from the demonstration of positive and negative transfer effects with intradimensional and extradimensional shifts. Much of the evidence has been reviewed by Wolff (1967) and Shepp \& Turrisi (1967).

The question to which this experiment is addressed asks if the memory of retardates is controlled by the same kinds of dimensions as those operating in attention. The answer might be inferred indirectly from the facts of intradimensional and extradimensional shifts: If the Ss learn to attend to relevant dimensions of stimuli, they must remember the dimensional information long enough to influence the dimensional transfer tests. But another, more direct test of dimensional control of retardate memory is possible, and has been arranged experimentally here. The retentional phenomenon of proactive interference provides the vehicle.

It will be shown that proactive interference develops over a series of discriminative problems within a single session, provided that all the problems within the series have a single relevant dimension. Interpolation, within the series, of a problem with a different relevant dimension causes a release from proactive interference.

The logic and experimental precedents for inferring proactive interference have been established largely by students of short-term memory in normal adult Ss recalling verbal material (e.g., Broadbent, 1958; Wickens, Born, \& Allen, 1963; Loess, 1964; Atkinson \& Shiffrin, 1968; and Turvey, 1968). Analogous rationales for inferring proaction in the visual discriminative learning of retardates have been described recently by Scott \& Scott (1969).

The design of this study is most easily represented by Table I showing the series of 10 different problems presented to each of two groups.

The seventh problem breaks the series. It is expected that as proaction develops over the first six problems, performance will decline as dimensional storage gets jammed. The seventh problem goes in to a different (hence emptier) short-term store, suffers less interference, and theoretically should restore original performance level. The last three problems should again demonstrate the lowered performance level associated with proactive interference.

$$
\text { METHOD }
$$

Two experiments were run, the second essentially a replication of the first, with minor differences in apparatus.

\section{Subjects}

Twenty retardates (10 in each experiment) within the MA range of 6-9 years were selected without regard to etiological category from the institutionalized population of the Longley School of the Mansfield State Training School. The mean MA was 7.0 years, mean CA 14 years, and mean IQ was 54 . Apparatus

In Experiment 1, a modified version of the Wisconsin General Test Apparatus was employed. In brief, the apparatus consisted of a manually operated tray with two candy wells covered by stimulus cards, one of which was to be chosen by the $S$ on each trial to find the one piece of candy hidden beneath the correct card. This apparatus has been described in detail by Zeaman \& House (1963).

In Experiment 2, the two stimulus figures were projected on translucent response panels, one of which delivered candy automatically in a cup between the two panels. This apparatus has been described by Scott (1966).

$$
\text { Stimuli }
$$

The stimuli were simple geometric forms and colors. Either color or form was made relevant by holding constant the other dimension; so, for instance, a form problem might be: red square vs red triangle, and a color problem: green diamond vs yellow diamond. Within the first six problems of a daily session, there was no repetition of color or form cues. The relevant cues on the critical seventh trial were also novel for that day. On repeated sessions for the same $S$, the specific cues were re-paired randomly from a population of 18 form and 12 color cues. In Experiment 2, the population consisted of 12 forms and 12 colors.

\section{Procedure}

Following a pretraining procedure. requiring the achievement of a criterion of $20 / 25$ correct on both a color and a form problem, the Ss were assigned without bias to experimental conditions.

The form group received daily for 10 days a session consisting of six two-trial problems with color constant, followed by a single two-trial problem with color relevant and form constant. The last three problems again had form relevant and color constant.

The color group had the same training as described above with "color" substituted for "form," as shown in Table 1. However, the last three problems re-paired cues previously presented in the first six problems.

A correction procedure was used throughout, with an M\&M candy as reward. Intertrial and interproblem intervals within a session were $20 \mathrm{sec}$.

$$
\text { RESULTS }
$$

The mean Trial 2 performance (as a measure of memory for Trial 1 information), averaged over 10 sessions for the $\mathrm{Ss}$ in both color and form groups, is graphed in Fig. 1 for both experiments. Problems have been blocked to eliminate irregularities. An initial decrement is shown by the drop in performance from the first to the second problem block. An increment is observed on Problem 7, with the change in relevant dimension, followed by a decrement in performance on the last problem block with the return to the originally relevant dimension.

The reliability of these effects is suggested by the similarity of outcomes of the experiment and its replication. A

Table 1

\begin{tabular}{|c|c|c|c|c|c|c|c|c|c|c|}
\hline & \multicolumn{10}{|c|}{ Sequences of Problems } \\
\hline & 1 & 2 & 3 & 4 & 5 & 6 & 7 & 8 & 9 & 10 \\
\hline $\begin{array}{l}\text { Color } \\
\text { Group }\end{array}$ & $\mathrm{C}$ & $\mathrm{C}$ & $\mathrm{C}$ & $C$ & C & C & $\mathbf{I}$ & C & $\mathrm{C}$ & $C$ \\
\hline $\begin{array}{l}\text { Form } \\
\text { Group }\end{array}$ & $\mathbf{l}$ & $F$ & 1 & $F$ & $1:$ & I & $\mathrm{C}$ & $\mathrm{J}$ & $\mathrm{I}$ & I: \\
\hline
\end{tabular}

Sequences of Two-Trial Problems with Relevant Dimensions of Color (c) or Form (f) Shifted on Problems 7 and 8 
simple statistical test was made of the reliability of each of the two main effects by applying a sign test (Siegel, 1956) to the number of $S s$ who did and did not show the initial proactive decline. and the relative number of $S s$ who showed the proactive release (i.c., Trial 7 higher than the average of Trials 6 and 8 ). In both cases, the sign test yielded probabilities lower than .05 associated with relevant null hypotheses.

\section{DISCUSSION}

The initial decline in performance over the course of the first six problems of each day is interpreted as the result of the development of proactive interference in short-term memory. The effect is short term in the sense that the interpolated interval of a day between sessions restores performance to its original level. The retentional nature of the finding is suggested in part by the decremental direction of the change. Other (nonretentional) interproblem transfer effects that migh be expected here-learning set or intradimensional shift-are incremental in effect.

Further evidence of the retentional nature of this proactive effect comes from a study by Knight (1968), who showed the temporal control of proaction. Very short intertrial intervals prevent proaction from developing. The conclusion is that the proactive effect is on retention rather than learning.

The increment on Trial 7 is interpreted as a release from proactive interference. To make a formal derivation of this effect, a short-term memory model is needed, such as that of Atkinson \& Shiffrin (1968), with the added assumption of separate buffer

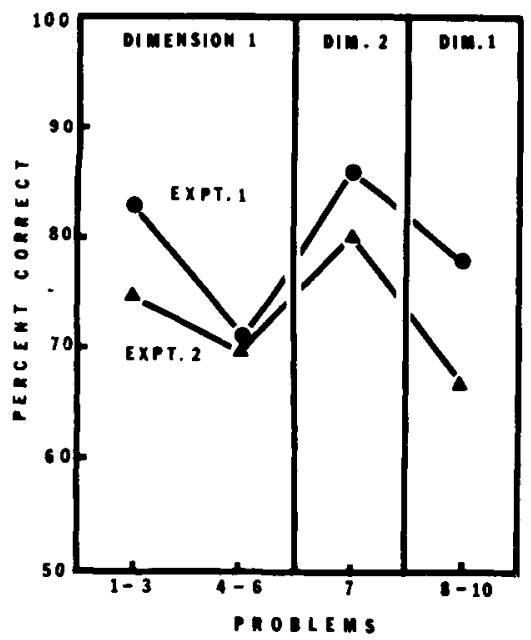

Fig. 1. Mean percentage correct performance on test trials of successive problems. Proaction develops over the first six problems, is released on Problem 7, and returns on the last three problems. storages for the dimensions of color and form. As the short-term storage for one dimension fills up and suffers interference, the other remains relatively empty and free of interference to give rise to the "release" phenomenon.

For a more complete account of the performance of retardates on discrimination problems of the type studied here, there is needed a composite of attention and retention models both of which use the same dimensions of stimuli.

\section{REFERENCES}

ATKINSON, R. C., \& SHIFFRIN, R. M. Human memory: A proposed system and its control processes. In K. W. Spence and J. T. Spence (Eds.). The psychology of learning and motilation. Vol. 2. New York: Academic Press. 1968. Pp. 89-195.

BROADBENT, D. B. Perception and communication. Oxford: Pergamon Press, 1958.

HOUSE, B. J., \& ZEAMAN, D. Miniature experiments in the discrimination learning of retardates. In L. P. Lipsitt and C. C. Spiker (Eds.). Advances in child development and behavior. Vol. 1. New York: Academic Press, 1963. Pp. 313-374.

KVilith II. $S$. The effects of inter-trial interval duration on short-term retention of a twochoice visual discrimination task by retarded children. Inpublished doctoral dissertation. Lniservity of Connecticut. 1968.

LOESS, H. Proactive inhibition in short-term memory. Journal of Verbal Learning \& Verbal Behavior, 1964, 3, 362-368.

SCOTT, K. G. Some parameters of short-term recall. Unpublished $\mathrm{PhD}$ dissertation, University of Connecticut, 1966.
SCOTT, K. G.. \& SCOTT, M. S. Research and theory in short-term memory. In N. R. Ellis (Ld.), International review of research in mental retardation. Vol. 3. New York: Academic Press, 1968. Pp. 135-157.

SHEPP, B. E., \& TURRISI, F. D. Learning and transfer of mediating responses in discrimination learning. In N. R. Ellis (Ed.), International review of research in mental retardation. Vol. 2. New York: Academic Press, 1967. Pp. 82-120.

SIEGEL, S. Nonparametric statistics for the behavioral sciences. New York: McGraw-Hill, 1956.

TURVEY, M. T. Analysis of augmented recall in short-term memory following a shift in connotation. British Joumal of Psychology, 1968, 59, 131-137.

WICKENS, D. D., BORN, D. G., \& ALLEN, C. K. Proactive inhibition and item similarity in short-term memory. Journal of Verbal Learning \& Verbal Behavior, 1963, 2, 440-445.

WOLFF, J. L. Concept-shift and discrimination-reversal learning in humans. Psychological Bulletin, 1967, 68, 369-408.

ZEAMAN, D., \& HOUSE, B. J. The role of attention in retardate discrimination learning. In N. R. Ellis (Ed.), Handbook of mental deficiency. New York: McGraw-Hill, 1963. Pp. 159-223.

\section{NOTE}

1. This research was carried out at the Mansfield State Training School, Mansfield Depot, Connecticut. The investigators wish to express appreciation for the active cooperation of Francis P. Kelley, Superintendent, and Louis Boly, Director of Training. This study was supported by Research Grants M1099 and K6-MH-HD-20,325 from the U.S. Public Health Service.

\section{The relative effectiveness of positive and negative information feedback in a concept attainment}

\section{task}

LINDA S. SIEGEL ${ }^{1}$ and JERROLD L. DOWNEY, University of Missouri, Columbia, Mo. 65201

The relative effectiveness of positive and negative verbal feedback was investigated in an attempt to ascertain whether the differential effect was due to reinforcement value of the feedback or to some difference in information gained from the feedback. College Ss solved a concept attainment task under one of two conditions: (1) right-nothing (R-N), feedback for correct responses onlv, or
(2) nothing-wrong (N-W), feedback for incorrect responses only. The expectation that, when the frequency of "right" and "wrong" feedback was controlled, there would be no difference between conditions was not supported, with $N-W \quad S s$ performing significantly better than $R-N$ Ss.

Investigations regarding the relative effectiveness of verbal feedback combinations in concept attainment have led to the suggestion (e.g., Buss \& Buss, 